\title{
ERRATUM
}

Indianization, the Officer Corps, and the Indian Army. By CHANDAR S. SUNDARAM. Lanham, Md.: Lexington Books, 2019. 284 pp. ISBN: 9781498579513 (cloth). - ERRATUM

\section{Pradeep Barua}

https://doi.org/10.1017/S0021911820001588, published by Cambridge University Press, 5 October 2020.

In the original publication of this review, the first name of the book's author, Chandar S. Sundaram, was misspelled in the review title, the first paragraph of the review, and a footnote citing the author's previous work.

The review has been updated. The editor and publisher apologize for this error.

\section{Reference}

Barda, Pradeer. 2020. Review of Indianization, the Officer Corps, and the Indian Army, by Chandar S. Sundaram. Journal of Asian Studies 79(3): 803-804. 